This item was submitted to Loughborough's Research Repository by the author.

Items in Figshare are protected by copyright, with all rights reserved, unless otherwise indicated.

\title{
The economic implications of alternative publishing models
}

PLEASE CITE THE PUBLISHED VERSION

PUBLISHER

Routledge (Taylor \& Francis)

VERSION

AM (Accepted Manuscript)

LICENCE

CC BY-NC-ND 4.0

REPOSITORY RECORD

Houghton, John, and Charles Oppenheim. 2019. "The Economic Implications of Alternative Publishing Models". figshare. https://hdl.handle.net/2134/6148. 
This item was submitted to Loughborough's Institutional Repository (https://dspace.lboro.ac.uk/) by the author and is made available under the following Creative Commons Licence conditions.

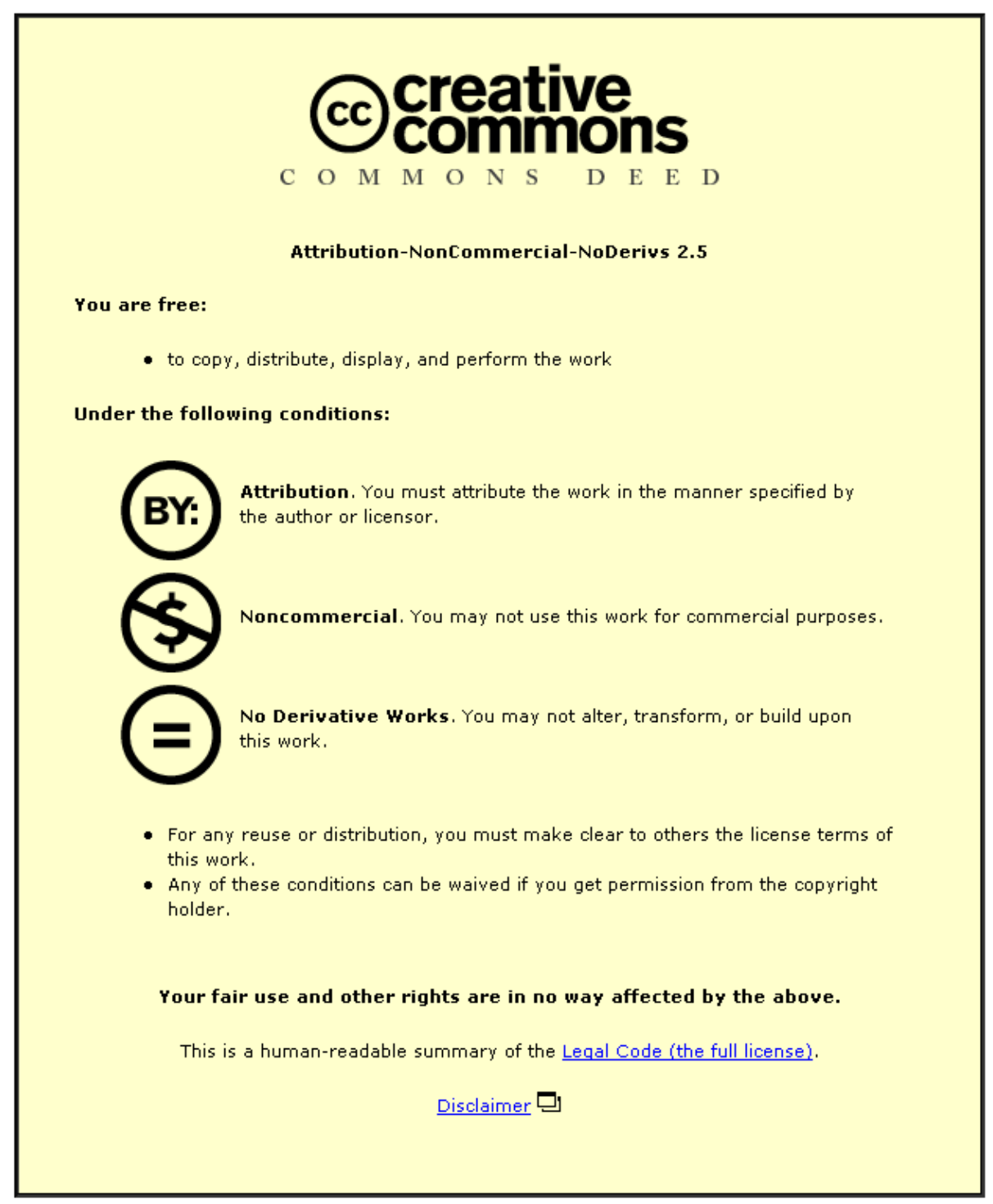

For the full text of this licence, please go to: http://creativecommons.org/licenses/by-nc-nd/2.5/ 


\title{
The Economic Implications of Alternative Publishing Models
}

\author{
John W. Houghton
}

Centre for Strategic Economic Studies, Victoria University, Melbourne

John.Houghton@vu.edu.au

And

Charles Oppenheim

Department of Information Science, Loughborough University

C.Oppenheim@lboro.ac.uk

(Approx: 3,500 words)

\begin{abstract}
A knowledge economy has been defined as one in which the generation and exploitation of knowledge has come to play the predominant part in the creation of wealth. It is not simply about pushing back the frontiers of knowledge; it is also about the more effective use and exploitation of all types of knowledge in all manner of economic activities. One key question is whether there are new opportunities and new models for scholarly publishing that might better serve researchers and more effectively communicate and disseminate research findings.

Building on previous work, this paper looks at the costs and potential benefits of alternative models for scientific and scholarly publishing, describing the approach and methods used and summarising the findings of a study undertaken for the Joint Information Systems Committee (JISC) in the United Kingdom. It concludes that different publishing models can make a material difference to the costs faced and benefits realised from research communication, and it seems likely that more open access to findings from publicly funded research would have substantial net benefits.
\end{abstract}

\section{Key Words}

Scientific and scholarly communication, economics of publishing, open access

\section{Acknowledgements}

Thanks are due to the research team from the JISC EI-ASPM project, including principal collaborator Charles Oppenheim of Loughborough University, Bruce Rasmussen and Peter Sheehan of The Centre for Strategic Economic Studies at Victoria University in Melbourne, and Anne Morris, Claire Creaser, Helen Greenwood, Mark Summers and Adrian Gourlay of Loughborough University, as well as members of the project advisory group. The team benefited from the very generous contributions of Bo-Christer Björk of the Hanken School of Economics in Helsinki and Donald King of the University of North Carolina. 


\section{Introduction}

A knowledge economy has been described as one in which the generation and exploitation of knowledge has come to play the predominant part in the creation of wealth. It is not simply about pushing back the frontiers of knowledge; it is also about the more effective use and exploitation of all types of knowledge in all manner of economic activities (Department of Trade and Industry 1998). Scholarly publishing plays a key role as it is central to the efficiency of research and to the dissemination of research findings and diffusion of scientific and technical knowledge. Recent advances in information and communication technologies are disrupting traditional publishing models, radically changing our capacity to reproduce, distribute, control and publish information. One key question is whether there are new opportunities and new models for scholarly publishing that might better serve researchers and more effectively communicate and disseminate research findings (OECD 2005, p14).

Building on previous work, this paper looks at the costs and potential benefits of alternative models for scientific and scholarly publishing. The work began in Australia in 2006 with a study of Research Communication Costs, Emerging Opportunities and Benefits (Houghton et al. 2006). This was followed by a study of the Economic Implications of Alternative Scholarly Publishing Models for the Joint Information Systems Committee (JISC) in the United Kingdom (Houghton et al. and Oppenheim et al. 2009). This paper describes the approach used and summarises the findings of the latter study.

\section{Alternative publishing models}

The JISC study focused on three alternative models for scholarly publishing, namely: subscription publishing, open access publishing and self-archiving.

- Subscription publishing refers primarily to academic journal publishing and includes individual subscriptions and the, so called, Big Deal (i.e. where institutional subscribers pay for access to online aggregations of journal titles through consortial or site licensing arrangements). In a wider sense, however, subscription publishing includes any publishing business model that imposes reader access tolls and restrictions on use designed to maintain publisher control over access in order to enable the collection of those tolls.

- Open access publishing refers primarily to journal publishing where access is free of charge to readers, while authors, their employing or funding organisations pay for publication, or the publication is supported by other sponsors making it free for both readers and authors. Use restrictions can be minimal as no access toll is imposed.

- Open access self-archiving refers to the situation where authors deposit their work in on-line open access institutional or subject-based repositories, making it freely available to anyone with Internet access. Again, use restrictions can be minimal.

Of itself, self-archiving does not constitute formal publication so analysis focuses on two publishing models in which self-archiving is supplemented by the peer review and production activities necessary for formal publishing, namely: (i) 'Green OA' self-archiving operating in 
parallel with subscription publishing; and (ii) the 'deconstructed' or 'overlay journals' model in which self-archiving provides the foundation for overlay journals and services (e.g. peer review, branding and quality control services) (Smith 1999; Van de Sompel et al. 2004; Smith 2005; Simboli 2005; Houghton 2005). Hence, each of the publishing models explored includes all of the key functions of scholarly publishing, including peer review and quality control.

\section{Approach and methodology}

The JISC project relied primarily on existing sources, collating activity cost information from the wide-ranging literature on scholarly publishing (e.g. Tenopir and King 2000 and subsequent tracking studies; Halliday and Oppenheim 1999; Friedlander and Bessette 2003; OECD 2005; European Commission 2006; Houghton et al. 2006; EPS et al. 2006; King 2007; Björk 2007; Clarke 2007; CEPA 2008; etc.). Where necessary, these sources were supplemented by informal consultation with experts in the field.

\section{Identifying costs and benefits}

The first phase of the JISC study sought to identify all the dimensions of cost and benefit associated with each of the models, and examine which of the main players in the scholarly communication system would be affected and how they would be affected by the adoption of alternative publishing models. In order to provide a solid foundation for analysis, we developed and extended the scholarly communication life-cycle model first outlined by Bo-Christer Björk (2007).

Björk (2007) developed a formal model of the scholarly communication life-cycle, based on the IDEF0 process modelling method often used in business process re-engineering, to provided a detailed map of the scholarly publishing process. Björk's central focus was the single publication (primarily the journal article), how it is written, edited, printed, distributed, archived, retrieved and read, and how eventually its reading may affect practice. Extending the model outlined by Björk, the scholarly communication process model developed for the JISC study included five core scholarly communication process activities, namely:

(i) Fund research and research communication;

(ii) Perform research and communicate the results;

(iii) Publish scientific and scholarly works;

(iv) Facilitate dissemination, retrieval and preservation; and

(v) Study publications and apply the knowledge (Figure 1).

Each of these is further subdivided into a detailed description of the activities, inputs, outputs, controls and supporting mechanisms involved (Erraguntla and Benjamin 2007). This formal 
process modelling was used to identify activities and provide the foundation for activity costing. ${ }^{1}$

Figure 1: $\quad$ The scholarly communication process

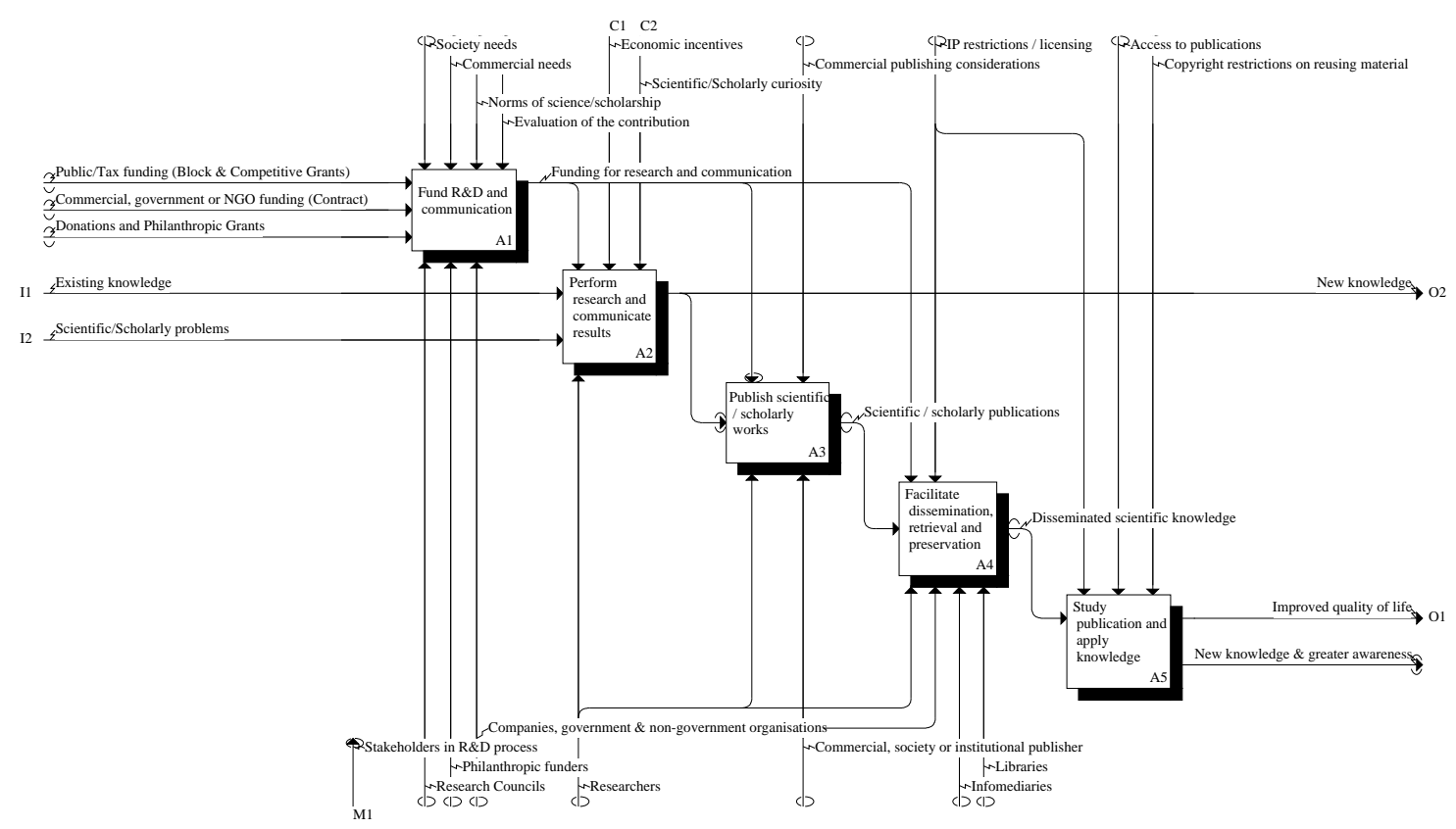

Note: Entire model at http://www.cfses.com/El-ASPM/SCLCM-V7I

Source: Houghton et al. and Oppenheim et al. (2009).

There are various ways to explore the impacts and possible benefits of alternative publishing models. Focusing on access and use, Houghton et al. (2006) noted that potential benefits include impacts relating to research use of the content, industry and government use, and use by the wider community. While providing a useful starting point, their analysis focused on use impacts and did not explore the production-side impacts.

Key issues in open access are access and permission, where access includes accessibility in the sense of the ease and affordability of access, and permission refers to permission to use the material in terms of what is permitted and the time and cost involved in checking and obtaining permission. This suggested an analysis along the overlapping dimensions of access and permission, mediated by cost in terms of both money and time - in essence, setting the alternative publishing models against the 'ideal' of open access for free, immediate and unrestricted access by exploring the time and cost involved in accessing and using scientific and scholarly works (Figure 2).

1 Details of the entire model in 'browseable' form can be found on the Web at http://www.cfses.com/EI-ASPM/SCLCM-V7/ 
Figure 2: Dimensions of impact: access and permission

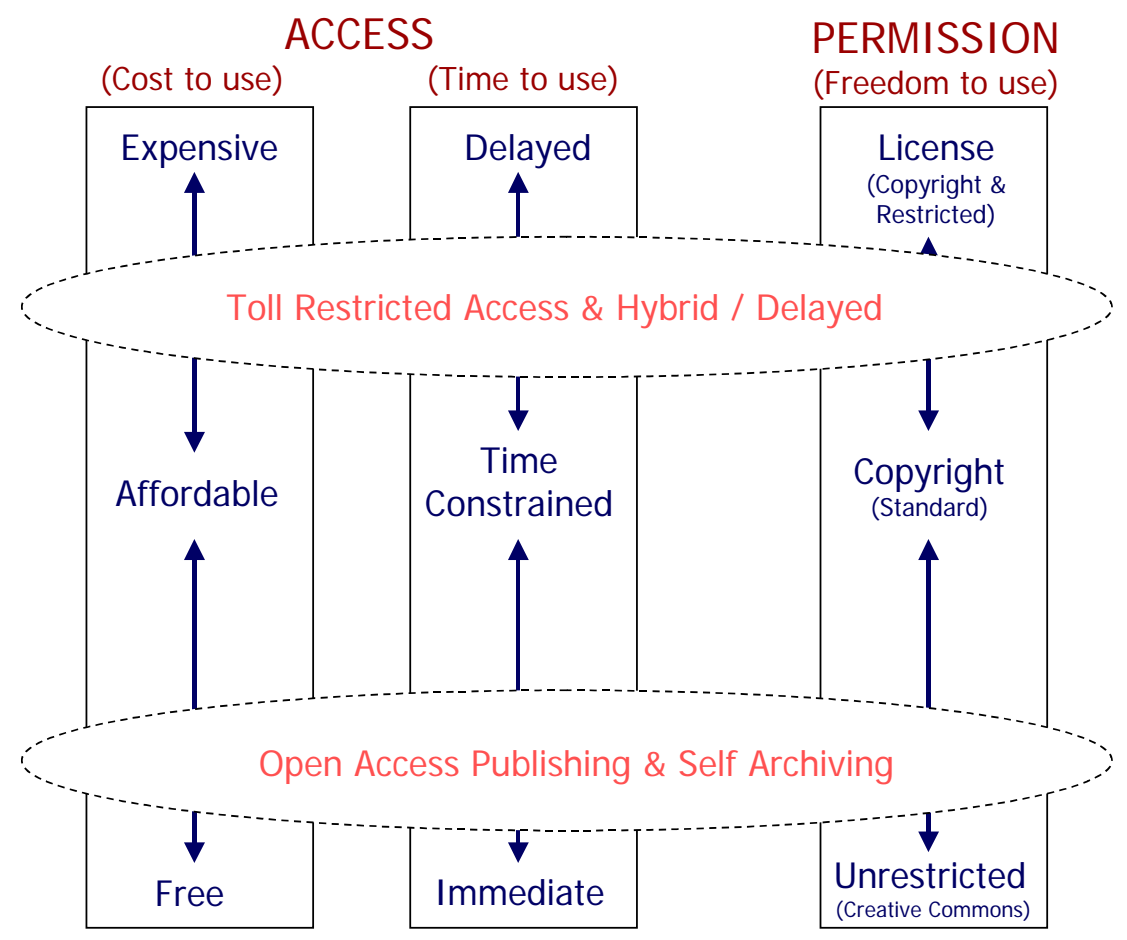

Source: Houghton et al. and Oppenheim et al. (2009).

Drawing on a number of previous reviews and following an established lead, Martin and Tang (2007) explored seven mechanism or channels through which the benefits of publicly funded research might flow through to the economy or to society more generally, namely:

- An increase in the stock of useful knowledge;

- The supply of skilled graduates and researchers;

- The creation of new scientific instrumentation and methodologies;

- The development of networks and stimulation of social interaction;

- The enhancement of problem solving capacity;

- The creation of new firms; and

- The provision of social knowledge.

While open access publishing models relate to research publications alone, enhanced access and reduced permissions barriers could be important in all of these (arguably, with the exception of the third). More open and less restricted access would effectively increase the stock of useful knowledge that is accessible to would-be users; contribute through impacts on education to enhancing the supply and skills of researchers; enable the development of networks on the basis of a access to shared, common and complete set of information; enhance problem solving capacity by providing the necessary supporting information; enable the provision of a range of social knowledge (e.g. in health care); and provide opportunities for the emergence of new firms 
and new industries (e.g. as happened in the case of Weather Derivatives (Pluijmers and Weiss 2005; Stell 2005)).

Of course, the principal input to the process of performing research and communicating the results is existing knowledge, as the production of knowledge depends, in large part, on its consumption. Hence, costs and benefits on the production-side also relate, in large part, to access and permission - the costs associated with limiting and managing access, copyright, licensing and permissions; and the cost savings (benefits) of not doing so. Indirect benefits also relate, in large part, to access and permission - the greater use, higher profile and higher impact/return for funders, researchers and research institutions, publishers and those facilitating dissemination, retrieval and preservation. Access and permission are crucial to the overall efficiency of the scholarly communication system.

Hence, our approach to exploring and quantifying costs, impacts and benefits is twofold. First, a detailed 'bottom up' costing that provides a foundation for the estimation of cost savings and the development of scenarios exploring impacts. Second, a 'top down' modelling of impacts of enhanced access on returns to R\&D through further development and application of the modified Solow-Swan model outlined by Houghton et al. (2006) and Houghton and Sheehan (2009).

\section{Quantifying costs and benefits}

The second phase of the JISC study sought to quantify the costs and benefits, identify and where possible quantify the cost and benefit implications for each of the main players in the scholarly communication system and, as far as possible, compare the costs and benefits of the three models. There are three elements to our approach to quantifying costs and benefits.

- First, we explored the costs of the process activities and then summed them to estimate system-wide costs. From that we can see cost differences and direct savings.

- Second, we presented cases and scenarios to explore the potential cost savings resulting from alternative publishing models (e.g. looking at impacts on search and discovery, library handling costs, etc.). From this we can explore indirect cost differences and savings.

- Third, we approached the issue from the top down and model the impact of changes in accessibility and efficiency on returns to R\&D using a Solow-Swan model, into which we introduce accessibility and efficiency as negative or friction variables to reflect the fact that there are limits and barriers to access and to the efficiency of production and usefulness of knowledge (Houghton and Sheehan 2009).

A full description of the modelling approach and details of its operationalisation can be found in Houghton et al. and Oppenheim et al. (2009). 


\section{Estimating activity and system costs}

In the first of these steps, we produced detailed costings of activities with a focus on cost differences between the three publishing models. One key challenge is to separate the cost impacts of publishing models from those of publishing format, so that we can explore the cost differences between subscription and open access publishing models independent of differences between print and electronic production. Our approach was to estimate costs for print, dualmode (i.e. parallel print and electronic production) and electronic-only formats for subscription and open access models, and then compare subscription and open access models as if they were all electronic or 'e-only'. All of the costings included commercial publisher margins.

For subscription publishing, we estimate an average publisher cost of around GBP 3,250 per article for dual-mode production, GBP 2,730 per article for print only production and GBP 2,335 per article for e-only production (excluding the costs associated with external peer review and Value-Added Tax) (Figure 3). ${ }^{2}$

For open access publishing, we estimate average per article costs at GBP 1,525 for e-only production. Excluding the costs of copy printing and delivery, we estimate the cost of dualmode open access publishing at around GBP 2,000 per article and print only open access publishing at GBP 1,830 per article. ${ }^{3}$

We included the implied publisher costs of overlay services to open access self-archiving (i.e. the overlay services model), with the same commercial management, investment and profit margins applied. This suggested that operating peer review management, editing, production and proofing as an overlay service would cost around GBP 1,125 per article excluding hosting, or GBP 1,260 including hosting.

2 These publisher costs are derived from those reported in the literature and are inflated where necessary and converted to pounds at 2007 annual average exchange rates.

3 It is impossible to estimate the cost of printing and delivery in open access publishing as it depends on the number of copies involved, and in the absence of subscriber counts that number cannot be known. Therefore, estimates for print and dual-mode open access publishing exclude actual copy print and delivery related costs, assuming that the content is produced print ready and print is an add-on. 
Figure 3: $\quad$ Estimated average publisher costs per article by format and model (GBP, circa 2007)

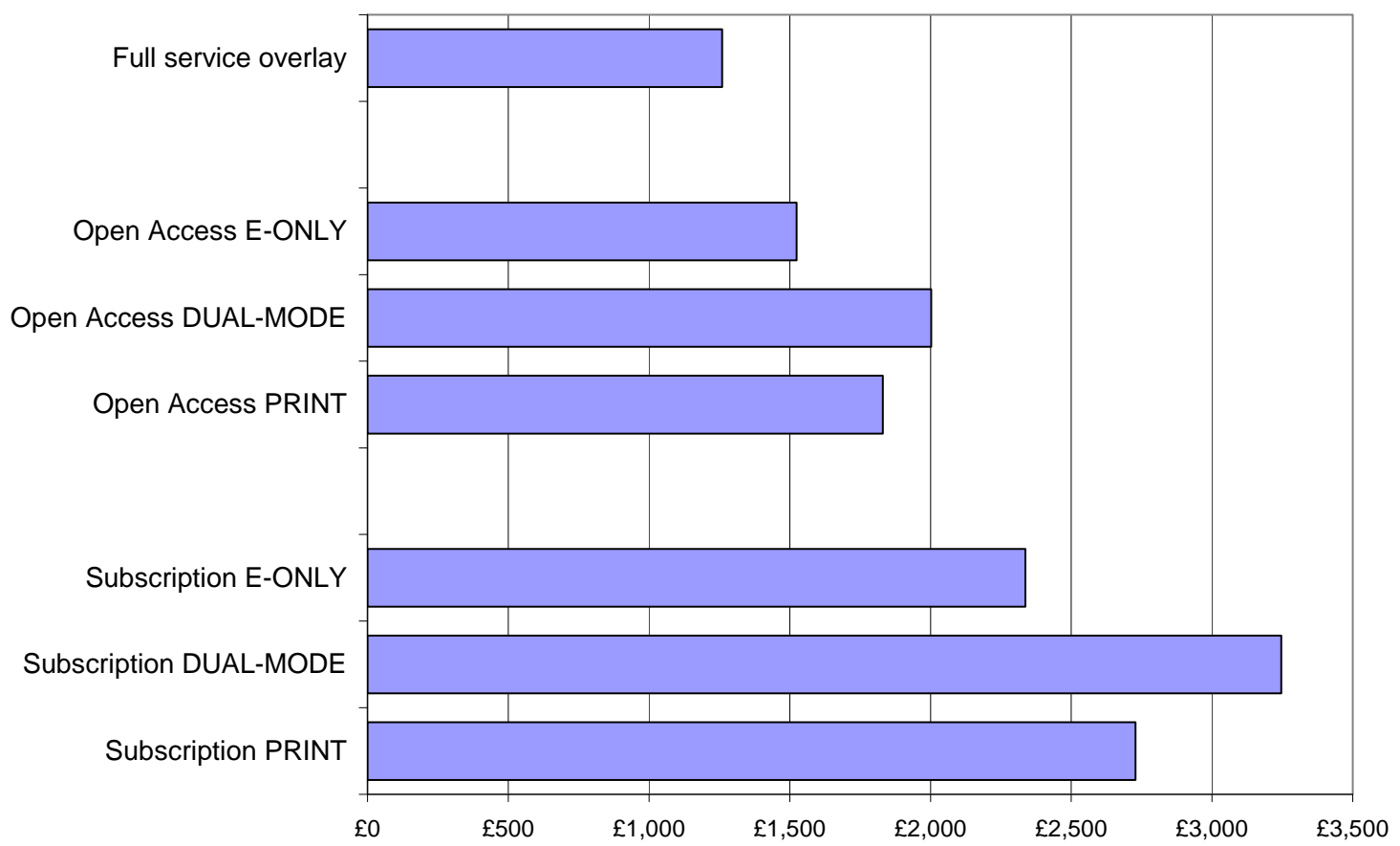

Note: These costs exclude the external costs of peer review and VAT. Overlay services include operating peer review management, editing, proofing and hosting, with commercial margins. Estimates for print and dual-mode open access publishing exclude copy print and delivery related costs, assuming that the content is produced print ready and print is an add-on.

Source: Houghton et al. and Oppenheim et al. (2009).

In the second of the three steps, we summed the per article costs of the three publishing models in electronic only format through the main phases of the scholarly communication life-cycle. ${ }^{4}$ We found that for UK higher education average subscription publishing system costs would amount to around GBP 8,295 per article (excluding VAT), average open access publishing costs would amount to GBP 7,485 per article and average open access self-archiving costs GBP 7,115 per article (including overlay review and production services with commercial margins). At these costs, open access publishing would be around GBP 815 per article cheaper than subscription publishing, and open access self-archiving with overlay services around GBP 1,180 per article cheaper (Figure 4). For UK higher education, these journal article cost differences would have amounted to direct savings of around GBP 80 million per annum circa 2007 from a shift from subscription to open access publishing, and GBP 116 million from a shift to open access self-archiving with overlay services.

4 The totals are intended to highlight differences between models and should not be taken as system costs without also taking account of the double-counting implicit in the full economic costing of researcher activities (e.g. including overhead costs in research activities taking place in institutions that contain research libraries). Moreover, costs relate to the outputs of each activity area, such that the costs of writing and reviewing are per manuscript written and reviewed, whereas publisher costs are per manuscript published. 
Figure 4: $\quad$ Scholarly communication system costs per article (GBP, circa 2007)

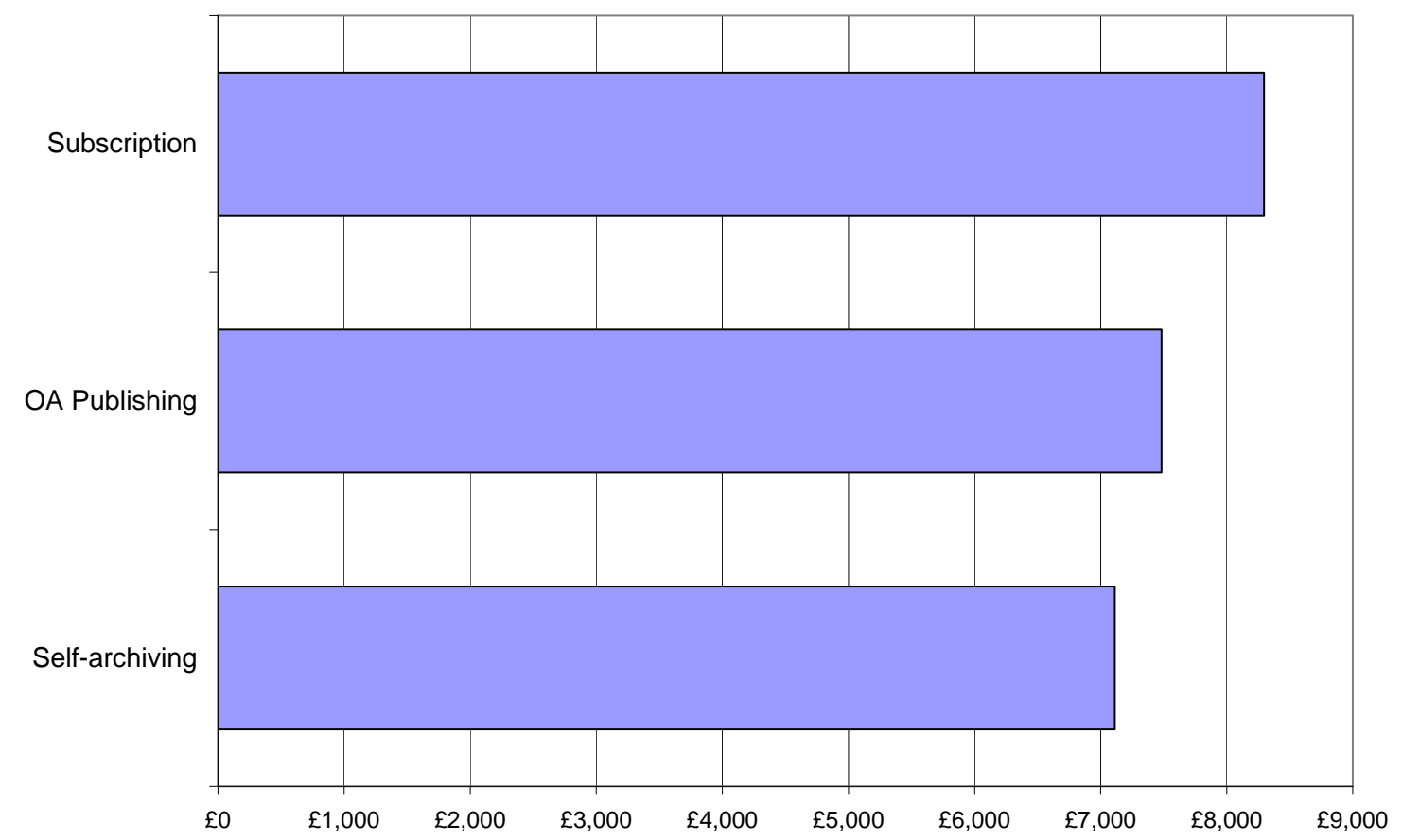

Note: Includes the direct costs of writing, peer review, publishing and disseminating in e-only format, and excludes VAT. Self-archiving includes publisher production and review costs, including commercial margins (i.e. overlay services).

Source: Houghton et al. and Oppenheim et al. (2009).

\section{Estimating system savings}

In addition to these cost differences there are potential system cost savings in such areas as library acquisition and handling, search, discovery access and research use, funding, reporting and evaluation. As many of the potential cost savings cannot be fully realised unless there is worldwide adoption of open access, we explored unilaternal national and worldwide adoption scenarios. In the unilateral national open access scenarios funder, research, library handling and subscription cost savings are scaled to the UK's article output (i.e. are in proportion to the share of worldwide journal literature that would be open access as a result of the unilateral adoption of alternative open access models by the UK). In the 'Green OA' model self-archiving operates in parallel with subscription publishing, so there are no publisher, library handling or subscription cost savings.

We estimated that open access publishing for journal articles using the 'author-pays' model might bring system savings of around GBP 500 million per annum nationally in the UK in a worldwide open access system (at 2007 prices and levels of publishing activity), of which around GBP 430 million would accrue in higher education. Open access self-archiving without subscription cancellations (i.e. 'Green OA') might save around GBP 108 million per annum nationally in a worldwide Green OA system, of which around GBP 75 million would accrue in higher education. The open access self-archiving with overlay services model explored is 
necessarily speculative, but would be likely to produce similar savings to open access publishing using the 'author-pays' model.

These savings can be set against the costs. We estimated that with author fees of GBP 1,500 per article published, open access publishing all journal articles produced would have cost around GBP 170 million nationally in 2007, of which GBP 150 million would have been faced by the universities. The operation of a system of open access institutional repositories in which all institutions operated a single repository and publications were self-archived once would have been likely to cost around GBP 22 million nationally and GBP 18 million for the universities.

\section{Estimating the impact of more open access on returns to $R \& D$}

In the third of the three major steps, we modify a basic Solow-Swan model to estimate the impacts of changes in accessibility and efficiency on returns to R\&D. The standard Solow-Swan approach makes a number of key simplifying assumptions, including that all $R \& D$ generates knowledge that is useful in economic or social terms (i.e. the efficiency of R\&D), and that all knowledge is equally accessible to all entities that could make productive use of it (i.e. the accessibility of knowledge). Addressing these assumptions, we introduced accessibility and efficiency as negative or friction variables, to reflect the fact that there are limits and barriers to access and to the efficiency of production and usefulness of knowledge. Then we explored the impact on returns to R\&D of reducing the friction by increasing accessibility and efficiency (Houghton and Sheehan 2009; Houghton et al. and Oppenheim et al. 2009).

We produced range estimates, looking at rates of return to R\&D from 20\% to 60\% (Geuna and Arundel 2003) and increases in access and efficiency of $1 \%$ to $10 \%$. For the purposes of discussion, based on an extensive review of the literature, we took the lower bound average $20 \%$ social return on public sector R\&D and suggested that a $5 \%$ increase in accessibility and efficiency might be plausible. Despite limitations in models of this type these model parameters are grounded and, if anything, may err on the conservative side. For example, the percentage change in accessibility and efficiency is based on metrics relating to: the share of publications in general and journals in particular in the research stock of knowledge; the share of the research stock of knowledge potentially available to open access; a number of proxy measures of accessibility, including UK research library subscriptions and conservative estimates of the open access citation advantage; and a number of estimates of the potential efficiency implications of access limitations, such as duplicative research, and of relaxing those limitations, such as speeding up the research and discovery process and facilitating greater collaboration (Houghton et al. and Oppenheim et al. 2009).

\section{Comparing costs and benefits}

First, we explored the benefit/cost implications of simply adding open access publishing and self-archiving to current activities, all other things remaining the same (i.e. ceteris paribus scenarios). Then we explored the implications of open access publishing and self-archiving as alternatives to current activities, by adding the estimated system savings to the estimated 
increases in returns (i.e. net cost scenarios). ${ }^{5}$ These benefit/cost comparisons suggest that the additional returns to R\&D resulting from enhanced accessibility and efficiency alone would be sufficient to cover the costs of parallel open access self-archiving without subscription cancellations (i.e. 'Green OA'). When estimated savings are added to generate net costs there is a substantial increase in the benefit/cost ratios, and for both open access publishing and selfarchiving alternatives (i.e. 'Gold OA' and 'Green OA') the benefits exceed the costs, even in a transitional period. Indicative modelling of post-transition 'steady-state' alternative systems suggests that, once established, alternative open access publishing and/or self-archiving systems would produce substantially greater net benefits.

For example, during a transitional period of 20 years we estimated that, in an open access world:

- The combined cost savings and benefits from increased returns to R\&D resulting from open access publishing all journal articles produced in the UK's universities using an 'author-pays' system would be around 3 times the costs;

- The combined cost savings and benefits from open access self-archiving in parallel with subscription publishing (i.e. 'Green OA') would be around 7 times the costs; and

- The combined cost savings and benefits from an alternative open access self-archiving system with overlay production and review services (i.e. 'overlay journals') would be around 4 times the costs (Table 1 ).

Indicative modelling of post-transition 'steady-state' alternative systems returned benefits of around 7 to 8 times costs for open access publishing and self-archiving with overlay services, and 40 times the costs for the 'Green OA' self-archiving.

5 Of course, the scenario adding open access publishing to current activities is 'unrealistic', as parallel publishing all articles in open access and subscription journals simultaneously would not be possible given the copyright demands of subscription publishing. 
Table 1: $\quad$ Summary of benefit/cost comparisons by scenario and model (GBP millions and benefit/cost ratio)

\begin{tabular}{|c|c|c|c|c|}
\hline \multirow[t]{2}{*}{ Scenario } & \multirow[b]{2}{*}{ Costs } & \multicolumn{2}{|r|}{ Benefits } & \multirow{2}{*}{$\begin{array}{r}\text { Benefit/Cost } \\
\text { Ratio } \\
\end{array}$} \\
\hline & & Savings & Returns & \\
\hline \multicolumn{5}{|l|}{ Ceteris Paribus Scenarios } \\
\hline \multicolumn{5}{|l|}{ Transitional Model: } \\
\hline OA Publishing in HE (unrealistic) & 1,787 & .. & 615 & 0.3 \\
\hline OA Publishing Nationally (unrealistic) & 2,079 & .. & 850 & 0.4 \\
\hline OA Self-archiving in HE & 189 & .. & 615 & 3.2 \\
\hline OA Self-archiving Nationally & 237 & .. & 850 & 3.6 \\
\hline \multicolumn{5}{|l|}{ Simulated Steady State Model: } \\
\hline OA Publishing in HE (unrealistic) & 1,787 & .. & 6,876 & 3.8 \\
\hline OA Publishing Nationally (unrealistic) & 2,079 & .. & 9,505 & 4.6 \\
\hline OA Self-archiving in HE & 189 & .. & 6,876 & 36.3 \\
\hline OA Self-archiving Nationally & 237 & .. & 9,505 & 40.0 \\
\hline \multicolumn{5}{|l|}{ Net Cost Scenarios } \\
\hline \multicolumn{5}{|l|}{ Scenario (UK Unilateral OA) } \\
\hline \multicolumn{5}{|l|}{ Transitional Model: } \\
\hline OA Publishing in HE & 1,787 & 2,990 & 615 & 2.0 \\
\hline OA Self-archiving in HE (Green OA) & 189 & 67 & 615 & 3.6 \\
\hline OA Self-archiving in HE (Overlay Services) & 1,558 & 2,990 & 615 & 2.3 \\
\hline OA Publishing Nationally & 2,079 & 3,479 & 850 & 2.1 \\
\hline OA Self-archiving Nationally (Green OA) & 237 & 96 & 850 & 4.0 \\
\hline OA Self-archiving Nationally (Overlay Services) & 1,831 & 3,479 & 850 & 2.4 \\
\hline \multicolumn{5}{|l|}{ Simulated Steady State Model: } \\
\hline OA Publishing in $\mathrm{HE}$ & 1,787 & 2,990 & 6,876 & 5.5 \\
\hline OA Self-archiving in HE (Green OA) & 189 & 67 & 6,876 & 36.7 \\
\hline OA Self-archiving in HE (Overlay Services) & 1,558 & 2,990 & 6,876 & 6.3 \\
\hline OA Publishing Nationally & 2,079 & 3,479 & 9,505 & 6.2 \\
\hline OA Self-archiving Nationally (Green OA) & 237 & 96 & 9,505 & 40.4 \\
\hline OA Self-archiving Nationally (Overlay Services) & 1,831 & 3,479 & 9,505 & 7.1 \\
\hline \multicolumn{5}{|l|}{ Scenario (Worldwide OA) } \\
\hline \multicolumn{5}{|l|}{ Transitional Model: } \\
\hline OA Publishing in HE & 1,787 & 5,198 & 615 & 3.3 \\
\hline OA Self-archiving in HE (Green OA) & 189 & 786 & 615 & 7.4 \\
\hline OA Self-archiving in HE (Overlay Services) & 1,558 & 5,198 & 615 & 3.7 \\
\hline OA Publishing Nationally & 2,079 & 6,054 & 850 & 3.3 \\
\hline OA Self-archiving Nationally (Green OA) & 237 & 1,132 & 850 & 8.3 \\
\hline OA Self-archiving Nationally (Overlay Services) & 1,831 & 6,054 & 850 & 3.8 \\
\hline \multicolumn{5}{|l|}{ Simulated Steady State Model: } \\
\hline OA Publishing in $\mathrm{HE}$ & 1,787 & 5,198 & 6,876 & 6.8 \\
\hline OA Self-archiving in HE (Green OA) & 189 & 786 & 6,876 & 40.5 \\
\hline OA Self-archiving in HE (Overlay Services) & 1,558 & 5,198 & 6,876 & 7.8 \\
\hline OA Publishing Nationally & 2,079 & 6,054 & 9,505 & 7.5 \\
\hline OA Self-archiving Nationally (Green OA) & 237 & 1,132 & 9,505 & 44.8 \\
\hline OA Self-archiving Nationally (Overlay Services) & 1,831 & 6,054 & 9,505 & 8.5 \\
\hline
\end{tabular}

Note: Compares open access alternatives against subscription access, with costs, savings and benefits expressed in Net Present Value over 20 years (GBP millions). Increased returns to R\&D relate to higher education R\&D expenditure (HERD) and national public expenditure on R\&D (PUBRD).

Source: JISC EI-ASPM model: Authors' analysis. 


\section{Conclusions}

The analysis summarised in this paper compares scholarly publishing models as if they were alternatives. In reality, of course, there are a number of variations and hybrids (e.g. delayed open access, open choice/author choice, etc.) and the models co-exist in various mixes in different fields of research. Nevertheless, the models do have some key defining characteristics, and these characteristics have cost implications for producers, intermediaries and the users and consumers of scientific and scholarly journal content. They also have implications for the efficiency of research, the accessibility of research findings and its impacts, and, thereby, for returns to investment in $R \& D$.

Our preliminary analysis of the potential benefits of more open access to research findings suggests that more open access would have substantial net benefits in the longer term, and while net benefits may be lower during a transitional period, they are likely to be positive for both open access publishing and self-archiving alternatives (i.e. Gold OA) and for parallel subscription publishing and self-archiving (i.e. Green OA).

\section{Reactions to the report}

Initial responses to the JISC report by Houghton et al. and Oppenheim et al. (2009) were polarised. Whilst many academics and funders welcomed the report, some individual scholarly publishers and their trade associations reacted negatively. However, many of their criticisms were aired in press releases, e-mails and electronic newsletters rather than in traditional scholarly fora.

Ware and Mabe (2009, p56) summarised the criticisms, noting that:

"[The Houghton Report] underestimated the efficiencies of the current subscription system and the levels of access enjoyed by UK researchers. Many of the savings hypothesized would depend on the rest of the world adopting author-pays or selfarchiving models. The calculated savings would remain hypothetical unless translated into job losses... Critics also argue that Houghton et al. underestimated the costs of switching to an author-pays model because they underestimated the true costs of publishing an article only, and because additional costs such as the infrastructure required to manage the many small publication charges were not included."

While referring to critics, Ware and Mabe (2009) fail to cite a single publication. This reflects the fact that criticisms have not appeared in traditional media, and are therefore difficult to address seriously. Nevertheless, JISC (2009) released a response addressing the criticisms soon after the release of the report.

The claim "... because additional costs such as the infrastructure required to manage the many small publication charges were not included" is oft-repeated, but is not correct, as a cost for author-side payments was included in the model. There were two considerations in estimating the costs involved in such transactions: (i) evidence of relevant transaction costs, and (ii) the number of transactions involved. Firstly, most of the major publishers offer pay-per-view for articles at around USD 30, suggesting that they can make transactions and some content revenue 
at USD 30 per transaction with people from all over the world with whom they have no preexisting business relationship. Secondly, publishers typically deal with the 'corresponding' or lead author of each paper, thus limiting transactions to one per published paper. The average number of papers per journal title per year (with large variation) is said to be of the order of 120, and while the average number of subscribers is less certain, a subscription journal that had fewer subscribers than papers in any given year would probably be in financial difficulty. Hence, the 'client' transaction costs of an author-pays journal are likely to be lower than those of a subscription journal, and the evidence from pay-per-view costs suggests that publishers' authorfee transaction costs might be of the order of USD 30 per paper published.

In short, the criticisms fall into two broad groups. The first is that certain costs have not been taken into account in the model; the second is that some of the figures input into the model are incorrect. If the publishers are confident about these criticisms, the way to deal with the matter is the one of normal scholarly discourse - i.e. publishers should develop their own model and/or use the Houghton model with their own figures, to see how the figures pan out. But they would have to do it by means of a scholarly publication, so that others can read about their methodology and learn what data was input. Unsubstantiated anonymous sniping at a report is not the way for constructive dialogue; the correct way is for publishers to publish their assumptions and results in an open and transparent manner so that scholars and other stakeholders can make an informed assessment.

\section{References}

Arundel, A. and Geuna, A. (2004). Proximity and the use of public science by innovative European firms, Economics of Innovation and New Technology 13(6), 2004, pp. 559-580.

Björk, B-C. (2007). A model of scientific communication as a global distributed information system, Information Research 12(2) paper 307, 2007.

Björk, B-C., Roos, A. and Lauri, M. (2009). Scientific journal publishing: yearly volume and open access availability, Information Research 14(1) March 2009.

CEPA (2008). Activities, costs and funding flows in the scholarly communications system in the UK, London: Research Information Network (RIN), May 2008.

Clarke, R. (2007). The cost profiles of alternative approaches to journal publishing, First Monday 12(12), December 2007.

Department of Trade and Industry (1998). Building the Knowledge Driven Economy: Competitiveness White Paper, London: Department of Trade and Industry.

EPS, et al. (2006). UK scholarly journals: 2006 baseline report - An evidence-based analysis of data concerning scholarly journal publishing, London: Research Information Network, Research Councils UK and Department of Trade and Industry.

Erraguntla, M. and Benjamin, P. (2007). Integrated activity based costing and activity modelling, Austin: Knowledge Based Systems. 
European Commission (2006). Study on the economic and technical evolution of the scientific publication markets in Europe, Brussels: European Commission.

Friedlander, A. and Bessette, R.S. (2003). The Implications of Information Technology for Scientific Journal Publishing: A Literature Review, Washington DC: National Science Foundation.

Gorman, G.E. and Rowland, F. (2005). International Year Book of Library and Information Management 2004-2005: Scholarly Publishing in an Electronic Era, London: Facet Publishing.

Geuna, A. and Arundel, A. (2003). Proximity and the Use of Public Science by Innovate European Firms, Royal Economic Society Annual Conference 2003 86, Royal Economic Society.

Halliday, L. and Oppenheim, C. (1999). Economic Models of the Digital Library, eLib, United Kingdom Office of Library and Information Networking.

Houghton, J.W. (2005). Economics of Publishing and the Future of Scholarly Communication, in eds. Gorman, G.E. and Rowland, F. International Year Book of Library and Information Management 2004-2005: Scholarly Publishing in an Electronic Era, London: Facet Publishing.

Houghton, J.W. Steele, C. and Sheehan, P.J. (2006). Research Communication Costs in Australia, Emerging Opportunities and Benefits, Canberra: Department of Education, Science and Training.

Houghton, J.W. and Sheehan, P.J. (2009). Estimating the Potential Impacts of Open Access to Research Findings, Economic Analysis and Policy 39(1), March 2009.

Houghton, J.W., Rasmussen, B., Sheehan, P.J., Oppenheim, C., Morris, A., Creaser, C., Greenwood, H., Summers, M. and Gourlay, A. (2009). Economic Implications of Alternative Scholarly Publishing Models: Exploring the Costs and Benefits, London and Bristol: The Joint Information Systems Committee (JISC).

JISC (2009) JISC Response to Feedback on the Economic Implications of Alternative Scholarly Publishing Models Report. Available http://www.jisc.ac.uk/media/documents/publications/responseoneiaspmreport.pdf

King, D.W. (2007). The cost of journal publishing: a literature review and commentary, Learned Publishing 20(2), April 2007, pp. 85-106.

King, D.W., Aerni, S., Brody, F., Herbison, M. and Kohberger, P. (2004). Comparative cost of the University of Pittsburgh electronic and print library collections, University of Pittsburgh, May 2004.

Martin, B.R. and Tang, P. (2007). The benefits of publicly funded research, SWEPS Paper No. 161, Science Policy Research Unit, Brighton: University of Sussex.

OECD (2005). Digital Broadband Content: Scientific Publishing, Paris: OECD. 
Pluijmers, Y. and Weiss, P. (2005). Borders in Cyberspace: Conflicting Government Information Policies and their Economic Impacts, April 2005.

Schonfeld, R.C., King, D.W., Okerson, A. and Fenton, G.E. (2004). The non-subscription side of periodicals: changes in library operations and costs between print and electronic journals, Washington DC: Council on Library and Information Resources.

Simboli, B. (2005). Subscription subsidized open access and the crisis in scholarly communication, Lehigh University.

Smith, J.W.T. (2005). Open Access Publishing Models: Reinventing Journal Publishing, Research Information, May-June 2005.

Smith, J.W.T. (1999). The Deconstructed Journal, a new model for Academic Publishing, Learned Publishing 12(2), 1999, pp. 79-91.

Stell, J. (2005). Results of the 2005 PwC Survey, Weather Risk Management Association, November 2005.

Tenopir, C. and King, D.W. (2000). Towards Electronic Journals: Realities for Scientists, Librarians and Publishers, Washington DC: Special Libraries Association.

Van de Sompel, H. et al. (2004). Rethinking Scholarly Communication: Building the system that scholars deserve, D-Lib Magazine 10(9) September 2004.

Ware, M. and Mabe, M. (2009) The stm report: An overview of scientific and scholarly journals publishing, Oxford: International Association of Scientific, Technical and Medical Publishers. 